\title{
BASES MOLECULARES DEL CÁNCER
}

\author{
Otto Gabriel Monzón MD*, Edmundo Mora Padilla MD**, Lilian Torres Tobar***, \\ Luz Dary Gutiérrez****, Cladelis Rubi****
}

\section{Resumen}

El cáncer es una enfermedad caracterizada por la proliferación anormal de células neoplásicas, dada en esencia por alteraciones genéticas y epigenéticas. El control de las diferentes funciones celulares está dado por los genes codificados en el ADN, por lo tanto algunas alteraciones en genes que codifican para las proteínas involucradas en el ciclo de proliferación celular pueden inducir una cascada de eventos que llevan a la producción del fenotipo cancerígeno. La transformación maligna requiere que ocurran alteraciones en genes específicos que controlan la proliferación celular, la apoptosis y el mantenimiento de la integridad del ADN en la misma célula. Las mutaciones tienen la posibilidad de aparecer de manera esporádica o de heredarse, pueden ser sustituciones de bases, adiciones, deleciones o cambios epigenéticos. El presente artículo revisa conceptos moleculares involucrados en la génesis del cáncer.

Palabras clave: cáncer, células neoplásicas, monoclonal, oncogenes, protooncogenes, genes supresores de tumores, genes de reparación de DNA, apoptosis, angiogénesis.

\section{THE MOLECULAR FUNDAMENTALS OF CANCER}

\begin{abstract}
Cancer is a disease featured by the abnormal proliferation of neoplastic cells mainly given by genetic and epigenetic alterations. The various functions of cells are controlled by the genes encoded in the DNA, thus, alterations in the genes encoded for the proteins involved in the cell proliferation cycle may be involved in a cascade of events which lead to the development of a cancer phenotype. Malignant transformation requires alterations to occur in specific genes which control cell proliferation, apoptosis and maintenance of the DNA integrity in the cell itself. Mutations may be inherited or may sporadically occur, they may be base substitutions, additions, deletions or epigenetic changes. This article reviews the molecular concepts involved in cancer progression.
\end{abstract}

Key words: cancer, neoplastic cells, monoclonal, oncogenes, proto oncogenes, tumor supresor genes, DNA repair genes, apoptosis, angiogenesis.

Fecha recibido: mayo 23 de 20II - Fecha acepmado: agosto II de 201 I

* Residente de Ginecología Oncológica, Instructor Asistente, Fundación Universitaria de Ciencias de la Salud, Bogotá DC. Colombia.

* Jefe de la Sección de Ginecología Oncológica, Hospital de San José. Profesor Asociado. Fundación Universitaria de Ciencias de la Salud. Bogotá DC. Colombia.
*** Coordinadora de Genética, Facultad de Medicina, Fundación Universitaria de Ciencias de la Salud. Investigador Grupo CBS. Bogotá DC. Colombia.

***** Instructor Asistente de Genética, Fundación Universitaria de Ciencias de la Salud. Investigador Grupo CBS. Bogotá DC. Colombia. 


\section{Introducción}

El cáncer es un problema de salud pública en todo el mundo y es la segunda causa de muerte en los Estados Unidos. ${ }^{1}$ Con el desarrollo de herramientas moleculares se ha logrado una mejor comprensión de las bases moleculares del cáncer. En general se presenta por la producción de defectos en genes específicos, que llevan a una proliferación celular incontrolada. Las alteraciones genéticas que juegan un papel importante son las involucradas en ganancia y pérdida de función de proteínas que regulan el ciclo de proliferación celular. En la actualidad se ha documentado un aumento en el número de síndromes hereditarios asociados con un mayor riesgo de cáncer. ${ }^{2}$

\section{Ciclo celular}

Es el proceso mediante el cual se da la proliferación celular. La función no es solo originar células nuevas, sino asegurar que el proceso se realice en forma adecuada. El ciclo celular se divide en dos grandes etapas: interfase y mitosis (M). La primera a su vez se subdivide en fase G1, S y G2 y la mitosis comprende la profase, metafase, anafase, telofase y citocinesis. ${ }^{2}$ La duración del ciclo y sus fases pueden variar dependiendo de la especie y del tipo de células. ${ }^{3}$ Según la capacidad que tiene una célula de realizar o no el ciclo celular se clasifican en tres tipos: a) las que tienen una alta especialización estructural como las nerviosas, musculares y eritrocitos, que maduran y pierden su capacidad de proliferación, b) las que normalmente no se dividen, pero están en capacidad de iniciar el ciclo celular hasta la mitosis en respuesta a estímulos específicos, como los hepatocitos y linfocitos y c) células con alta capacidad de proliferación como las epiteliales. ${ }^{4-6}$

En la fase G1 se produce el incremento del tamaño celular y la acumulación de ATP necesaria para el proceso de división celular, la fase $\mathrm{S}$ se caracteriza por la replicación del ADN y la G2 es donde la célula se prepara para el proceso de mitosis. Durante la división celular (M) la cromatina duplicada con anterioridad se divide de modo tal que cada célula hija obtenga una copia idéntica del ADN. ${ }^{2.3}$ Algunas células pueden entrar en una fase de estado de reposo, denominada fase G0, en la cual la célula puede permanecer por días, meses y hasta varios años. ${ }^{2-4}$

El ciclo celular es un proceso sujeto a regulación, la cual se lleva a cabo por puntos de control o de chequeo, que pueden inhibir o estimular diversos procesos que le permiten a la célula proseguir con su ciclo normal de replicación del material genético, crecimiento y división celular. La función de regulación, en esencia se realiza por proteínas conocidas como ciclinas y cinasas dependientes de ciclinas. ${ }^{7}$ En un organismo multicelular es de gran importancia que los diferentes tipos celulares se dividan a una velocidad suficiente, produciendo las células necesarias para el crecimiento y el remplazo de algunas que sufrieron los procesos de muerte celular. Si hay un desequilibrio, por ejemplo, un aumento exagerado de la proliferación celular cuando es innecesario, conlleva al mal funcionamiento del órgano involucrado y por último del organismo, siendo este un ejemplo de los acontecimientos en algunos tipos de cáncer. ${ }^{4,8,9}$

\section{Regulación del ciclo celular}

El sistema de control del ciclo celular está compuesto por ciertos factores de freno, que pueden parar el ciclo celular en unos puntos de chequeo determinados. Estos puntos actúan en momentos cruciales del ciclo celular, es decir, en el período entre el final de una fase y el inicio de la siguiente..$^{5,7,10} \mathrm{El}$ primer punto de control se encuentra en G1 antes de entrar en fase $\mathrm{S}$, otro en $\mathrm{G} 2$ antes de la mitosis y el último en fase $\mathrm{M}$ entre metafase y anafase, la función de este punto de chequeo es revisar que los cromosomas se hayan unido al huso mitótico. Por otro lado, en estos puntos de chequeo también se examina el estado metabólico, la masa celular y el estado del ADN, entre otros, para que se lleve a cabo un ciclo celular normal. ${ }^{10,11,12}$

El sistema de control del ciclo está basado en dos familias de proteínas: a) las cinasas dependientes de ciclina (CDKs), que son reguladas por fosforilación y defosforilación en los aminoácidos serina y treonina, lo que les permite activarse o no durante el ciclo celular, b) 
las ciclinas (cdc), denominadas así ya que aparecen y desaparecen a lo largo del ciclo. Además, estas proteínas se unen a las CDKs y controlan sus reacciones de fosforilación; en esta forma el ensamblaje cíclico entre estas dos proteínas, ciclinas y CDKs, induce la proliferación celular y el desensamblaje a su freno..$^{2,3,13-15}$

\section{Alteraciones esenciales para la transformación maligna}

Se han propuesto varios marcadores en la célula neoplásica, los cuales constituyen una forma organizada de entender la diversidad de anormalidades que suceden en los diferentes tipos y subtipos de cáncer. ${ }^{16}$

\section{Alteraciones en las señales de crecimiento}

Las células tumorales tienen la capacidad de crecer sin estímulo externo, con señales propias de moléculas que facilitan o promueven la proliferación y disminuyen la muerte o apoptosis. En el tejido normal la proliferación está dada principalmente por el acoplamiento de factores de crecimiento a sus receptores ubicados en la membrana celular, lo cual estimula al receptor que a su vez activa proteínas citoplasmáticas permitiendo la comunicación hacia el interior del citoplasma y luego hacia el núcleo, vía segundos mensajeros y factores de transcripción que estimulan la activación de la transcripción de los genes encargados de la proliferación celular. ${ }^{3}$ En la célula neoplásica este evento se altera por diversas mutaciones en genes que codifican las proteínas que participan en esta vía de señalización, lo que lleva a un aumento sostenido de la proliferación celular. $^{3}$

Algunos genes que participan en esta vía son los denominados protooncogenes, cuya función normal está relacionada con el crecimiento y proliferación celular. Cuando estos genes mutan se convierten en oncogenes y codifican oncoproteínas que facilitan y estimulan el crecimiento celular. Estas oncoproteínas funcionan como ligandos o factores de crecimiento, receptores de los factores de crecimiento, transductores de señales citoplasmáticas o factores de transcripción. ${ }^{10}$
Algunos protooncogenes que codifican para los receptores de factor de crecimiento son proteínas transmembrana con un dominio externo fijador del ligando y otro dominio citoplasmático tirosina-cinasa. En las formas normales, la cinasa se activa de forma transitoria mediante la unión del factor de crecimiento específico, seguido por la dimerización del receptor y la fosforilación de la tirosina como parte de la cascada de señales indispensables para la proliferación celular. Las versiones oncogénicas de estos receptores se asocian con la dimerización permanente y la activación de la señal sin necesidad de que ocurra la unión del receptor con el factor de crecimiento. La autosuficiencia en el crecimiento es característica de las células tumorales, que adquieren la capacidad de sintetizar los mismos factores a los que responden produciendo proliferación celular. Un ejemplo de estas oncoproteínas es el receptor del factor de crecimiento derivado de plaquetas. ${ }^{17}$

Otro ejemplo de la autosuficiencia adquirida por la célula tumoral es el protooncogen Ras, un péptido intercambiador de nucleótidos que se encuentra anclado a la membrana citoplasmática y oscila entre un estado activo e inactivo. En la forma inactiva fija GDP y cuando se activa por factores de crecimiento el GDP se fosforila a GTP. Esta proteína Ras unida a GTP actúa sobre la vía de las MAP quinasas, las cuales activan factores de transcripción nuclear que favorecen la mitosis. ${ }^{18}$

Las GTPasas (GAP) son enzimas encargadas de hidrolizar GTP a GDP para volver a Ras a su forma inactiva, llevando así a la finalización de la transducción de la señal. Las GAP funcionan como frenos que impiden la actividad incontrolada de Ras. Una mutación puntual que sustituye la glicina en posición doce de la proteína por cualquier otro aminoácido, hace innecesaria la señalización de acoplamiento del ligando al receptor, induciendo activación permanente de esta vía de señalización. ${ }^{18}$

Otra de las alteraciones de las señales de crecimiento puede involucrar factores de transcripción. Estas proteínas penetran en el núcleo y actúan sobre un gran número de genes que cuando se expresan marcan el 
inicio y la progresión de la célula en el ciclo celular, dando lugar a la replicación del ADN y por último a la mitosis. Los factores de transcripción contienen secuencias o grupos de aminoácidos específicos que les permiten unirse al ADN y de esta forma activar o inhibir la transcripción de genes que participan en la proliferación celular o en el mantenimiento de la integridad del $\mathrm{ADN} .{ }^{19}$ Un gran número de factores de transcripción como los de las familias Myb, Myc, Jun y Fos se encuentran alterados en la gran mayoría de tumores. ${ }^{19}$ Las alteraciones de los protooncogenes son dominantes sobre su variante sana y produce ganancia de la función de la proteína, es decir, activación permanente de señales de estímulo de la proliferación celular. ${ }^{2}$

\section{Pérdida de sensibilidad a las señales inhibidoras del crecimiento}

El crecimiento y desarrollo normal dependen de una adecuada regulación entre estímulo y freno de la proliferación celular. Las proteínas que participan en las señales inhibitorias del crecimiento celular son producto de los genes supresores de tumor. Estudios moleculares han identificado hasta la fecha más de 17 genes supresores de tumores implicados en forma directa en el cáncer. ${ }^{20}$ Ellos codifican para una serie de proteínas localizadas en distintas regiones de la célula, tanto en el citoplasma como en el núcleo. Los dos más caracterizados codifican para las proteínas p53 y pRB. ${ }^{20-24}$

La susceptibilidad para formar tumores cuando algún o algunos de los genes supresores de tumor están involucrados puede ser mediante la teoría del "doble golpe", es decir, uno de los alelos mutados es heredado a través de la línea germinal (herencia de uno de los padres) y un segundo cambio o mutación somática ocurre de manera espontánea en algún momento de la vida del individuo. La presencia y desarrollo del tumor está relacionada con la presencia de los dos eventos, es decir, de la alteración de forma homocigota. ${ }^{25-28}$

Algunos de los genes supresores de tumor expresan proteínas de acción citoplasmática: DPC4 codifica para una proteína de función en la ruta de señalización que inhibe la división celular, mutaciones en este gen se han encontrado en pacientes con cáncer de páncreas. NF- 1 codifica para una proteína que inhibe (Ras), involucrado en neurofibroma y feocromocitoma (cánceres del sistema nervioso periférico) y leucemia mieloide. NF-2 involucrado en meningioma, ependimoma y schwannoma. ${ }^{29}$

Algunos de los genes supresores de tumor expresan proteínas de acción a nivel del núcleo: MTS1 codifica para la proteína $\mathrm{p} 16$. RB codifica para la proteína $\mathrm{pRB}$, uno de los principales controles del ciclo celular. Las mutaciones en RB se encuentran presentes en pacientes con retinoblastoma y cánceres de hueso, vejiga, seno y de células pequeñas del pulmón. TP53 codifica para la proteína p53, involucrada en una gran cantidad de cánceres y WT1 en el tumor de Wilms del riñón. ${ }^{30}$

\section{Evasión de la apoptosis}

La idea acerca de la influencia de la apoptosis sobre el fenotipo maligno de la mayoría de los tumores surgió a principios de los años 70. ${ }^{31}$ Se apoyó en experimentos que demuestran que la muerte celular, al igual que cualquier proceso metabólico, es un gran programa regulado por vía genética que influye tanto en la supervivencia de la célula como en el control de la proliferación y la diferenciación. ${ }^{32}$

La alteración de estímulos pro y antiapoptóticos tanto internos como externos y la aparición de mutaciones en los genes que regulan este proceso llevan a la progresión tumoral. Entre los factores externos capaces de inducir apoptosis está la disponibilidad limitada de nutrientes, la carencia de factores de crecimiento, la disminución de oxígeno y la pérdida de las interacciones de matriz extracelular, entre otros. Los estímulos internos resultan aún más importantes en el desarrollo de algunos tumores al limitar su crecimiento en etapas tempranas o tardías cuando comienza la metástasis. ${ }^{32}$

La célula tumoral durante el proceso de progresión tumoral adquiere un fenotipo caracterizado no solo 
por la falta de respuesta ante señales de inhibición por contacto y de proliferación de manera incontrolada, sino que posee la capacidad adaptativa de sobrevivir y expandirse en forma clonal al tener alterado el programa de muerte celular programada, lo que hace que se produzca un desequilibrio entre proliferación y muerte celular, característica del cáncer. ${ }^{32}$

Las células en un organismo forman una comunidad organizada, donde el número de células está regulado; si una célula ya no se requiere, entra en un proceso de apoptosis, ${ }^{17}$ que es ordenado y con programación genética donde no hay liberación de componentes celulares al espacio extracelular ni daño a células vecinas. ${ }^{32-34}$

Genes que codifican para proteínas que participan en la apoptosis: la maquinaria molecular apoptótica está compuesta por componentes efectores y reguladores que actúan en una cascada de señalización, cuyo fin es controlar la muerte celular programada, ya sea actuando como reguladores negativos o positivos y efectores de la apoptosis. ${ }^{32}$

Los reguladores a su vez se dividen en dos circuitos de señalización: las proteínas involucradas que reciben y procesan señales externas que inducen la muerte celular (programa apoptótico extrínseco) y aquellas que reciben e integran una gran variedad de señales de origen intracelular (programa intrínseco). ${ }^{35}$ Cada una de estas vías termina en la activación de proteínas efectoras denominadas caspasas, las cuales inician una cascada de proteólisis para activar la fase ejecutora de la apoptosis. En esta etapa la célula en forma progresiva se desensambla y fragmenta, y los cuerpos apoptóticos resultantes son fagocitados por las células vecinas. ${ }^{32,33}$

Una molécula clave que inicia el proceso de apoptosis es la proteína p53 (codificada por el gen TP53) que aumenta la transcripción de genes proapoptóticos como Bax. La alteración de p53 cambia la transcripción de Bax reduciendo la actividad apoptótica. ${ }^{35}$ La proteína MDM2 interactúa en forma directa con p53 e influye de manera negativa porque regula la vida media de p53, su localización subcelular, su estabilidad y su capacidad para actuar como factor de transcripción. ${ }^{35-38}$

\section{Alteración en la reparación del ADN}

El ADN está expuesto en forma continua a factores ambientales que inducen alteración de su estructura, como son la radiación ionizante, la luz solar o los carcinógenos de la dieta, entre otros. Sin embargo, la célula posee un mecanismo muy especializado encargado de la reparación de los daños generados en el ADN y de esta forma evitar el acúmulo de mutaciones que desencadenan inestabilidad genómica. ${ }^{39}$ En la célula existen por lo menos seis mecanismos de reparación de ADN: por recombinación homóloga, escisión de nucleótidos, escisión de bases, reversión directa, malos apareamientos y de la unión de extremos. ${ }^{39}$

Reparación por escisión de nucleótidos: esta vía está determinada por tres genes denominados uvrA, uvrB y uvrC. El sistema reconoce cualquier lesión que cree una distorsión importante en la doble hélice de ADN y una endonucleasa denominada nucleasa uvrABC realiza una incisión, alejada varios pares de bases en cualquier lado de la base dañada, eliminándose a continuación un fragmento de ADN de cadena sencilla. El hueco generado se rellena mediante síntesis de ADN y luego se sella por la ligasa de ADN. ${ }^{40}$

La reparación por recombinación homóloga es un tipo arreglo en donde la hebra dañada se repara mediante el uso de la hebra del cromosoma homólogo no dañado como plantilla, es un tipo de reparación que se da posreplicación. El proceso incluye ruptura física del ADN dañado, replicación y ligamiento del ADN replicado. Si bien es muy utilizada para reparar las rupturas de cadenas dobles del ADN, la recombinación homóloga también produce nuevas combinaciones de secuencias de ADN durante el entrecruzamiento cromosómico en la meiosis. ${ }^{41-43}$

\section{Potencial replicativo ilimitado}

Tras un número fijo de divisiones, las células normales se detienen en un estado terminal o de quiescencia conocido como senescencia replicativa. Esta fase celular es determinada por el acortamiento de los telómeros en 
cada división celular que se lleva a cabo hasta el punto en donde no se involucre material genético que codifique para genes relacionados con el funcionamiento celular. Cuando esto sucede se activan los puntos de control del ciclo celular dependientes de p53 llevando a la apoptosis celular, lo que se denomina reloj biológico. ${ }^{44}$ Durante la embriogénesis y en células con altas tasas de replicación celular no hay acortamiento de los telómeros por la expresión y activación de una proteína conocida como telomerasa. Esta proteína mantiene los telómeros elongados y por lo tanto no hay senescencia celular. En el $90 \%$ de los tumores estudiados se ha detectado reactivación y aumento en la expresión de la telomerasa, lo que hace que la célula cancerígena pueda replicarse de forma indefinida. ${ }^{44,45}$

\section{Angiogénesis sostenida}

Similar al tejido normal, los tumores necesitan obtener nutrientes y oxígeno, así como eliminar desechos metabólicos y dióxido de carbono. La neovasculatura asociada con el tumor da respuesta a estas necesidades. Por lo tanto, durante la progresión de la neoplasia hay un aumento en la formación de nuevos vasos mediante la producción de la célula cancerígena de factores de crecimiento vasoendotelial que estimulan el crecimiento de los vasos sanguíneos del huésped y por la inhibición de proteínas que regulan en forma negativa la formación de nuevos vasos en tejido adulto (ejemplo, la trombospondina 1: TSP-1). Los tumores no pueden aumentar su tamaño más de 1 ó $2 \mathrm{~mm}$ de diámetro a menos que estén vascularizados, por esto la angiogénesis es una condición para el crecimiento del tumor y la metástasis. Los vasos cancerígenos son diferentes a los normales por ser tortuosos e irregulares, carentes de capa media. ${ }^{46-48}$

Durante mucho tiempo se supuso que las leucemias y otras enfermedades hematológicas se diferenciaban de las neoplasias sólidas por no estimular ni requerir angiogénesis. Sin embargo, ese concepto ha cambiado en forma radical en los últimos años. Así, en 1993 Folkman planteó que las leucemias podían ser angiogénesis-dependientes. Esa hipótesis se basó en sus propios hallazgos de niveles elevados anormales del factor de crecimiento de fibroblastos básico (b-FGF) en orina de pacientes leucémicos. ${ }^{49,50}$

Las células tumorales tienen una alta frecuencia de mutaciones, las que a su vez motivan la generación de resistencia a la terapia. Por el contrario, la célula endotelial presenta una baja frecuencia de mutagénesis y ello la hace mejor blanco terapéutico..$^{51-53}$

Como el bloqueo del crecimiento tumoral requiere de la inhibición del reclutamiento vascular, proceso conocido como angiostasis, la identificación y caracterización de moléculas angiostáticas con baja o nula toxicidad podría llegar a implicar un cambio en la terapia contra el cáncer. ${ }^{54}$

\section{Invasión y metástasis}

La última capacidad que debe adquirir la célula tumoral es la de salir del sitio de origen, migrar y establecerse en otros sitios para generar un nuevo tumor. El neo primario tiene una población de células heterogéneas con distintas alteraciones genéticas que permiten superar la inhibición del crecimiento dado por uniones intercelulares, diseminarse y colonizar órganos distantes. En el tumor primario las uniones intercelulares son reducidas debido a la pérdida de cadherina $\mathrm{E}^{55}$, proteína importante para el mantenimiento de la unión entre células. La adquisición de alteraciones en el gen que codifica esta proteína es un punto clave para transición de la célula epitelial a fenotipo mesenquimal, lo que la capacita para desanclarse e invadir el vaso sanguíneo y hacer metástasis. ${ }^{56}$

Por último para que las células tumorales puedan escapar de una masa primaria, entren en los vasos sanguíneos o linfáticos y produzcan un crecimiento secundario en un sitio distante, deben cumplirse los siguientes pasos: expansión clonal y angiogénesis, invasión y adhesión a la membrana basal, diseminación hacia la matriz extracelular, extravasación, interacción con células linfoides del huésped, depósito metastásico, angiogénesis y crecimiento. ${ }^{56}$ 


\section{Referencias}

1. Myers MH, Ries LA. Cancer patient survival rates: SEER program results for 10 years of follow-up. CA Cancer J Clin. 1989 JanFeb;39(1):21-32.

2. Alberts B, Bray D, Lewis J, Rafft M, et al. Biología molecular de la célula. 4a ed. Barcelona: Omega; 2004. 1463 p.

3. Cooper GM. The cell, a molecular approach. Washington: ASM Press; 1999.

4. Lewin B. Genes. 5th ed. New York : Oxford University; 2000.

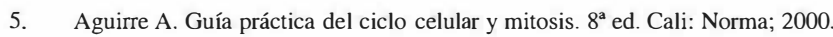

6. Xia H, Qi H, Li Y, Pei J, Barton J, Blackstad M, Xu T, Tao W. LATSI tumor supresor regulates G2/M transition and apoptosis. Oncogene.. 2002 Feb 14; 21(8):1233-41.

7. Nasmyth K. Viewpoint: putting the cell cycle in order. Science. 1996 Dec 6; 274(5293):1643-5

8. Celada A. Factores de transcripción y control de la expresión génica. Invest. cienc. 1991; 179: 42-51.

9. Kohn EA, Ruth ND, Brown MK, Livingstone M, Eastman A. Abrogation of the $S$ phase DNA damage checkpoint results in $S$ phase progression or premature mitosis depending on the concentration of 7-hydroxystaurosporine and the kinetics of Cdc25C activation. J Biol Chem. 2002 Jul 19;277(29):26553-64.

10. Darzynkiewicz Z, Smolewski P, Bedner E. Use of flow and laser scanning cytometry to study mechanisms regulating cell cycle and controlling cell death. Clin Lab Med. 2001 Dec;21(4):857-73.

11. Fisher DE. Pathways of apoptosis and the modulation of cell death in cancer. Hematol Oncol Clin North Am. 2001 Oct;15(5):931-56, ix.

12. Black JD. Protein kinase C-mediated regulation of the cell cycle. Front Biosci. 2000 Apr 1;5: D406-23.

13. Zink D, Mayr C, Janz C, Weismuller L. Association of p53 and MSH2 with recombinative repair complex during $S$ phase. Oncogene. 2002; 21: 4788-800.

14. Fisher DE. Pathways of apoptosis and the modulation of cell death in cancer. Hematol Oncol Clin North Am. 2001 Oct;15(5):931-56.

15. Orlowski CC, Furlanetto RW. The mammalian cell cycle in normal and abnormal growth. Endocrinol Metab Clin North Am. 1996 Sep;25(3):491-502.

16. Hanahan D, Weinberg RA. The Hallmarks of cancer. Cell. 2000 Jan 7;100(1):57-70.

17. Crighton D, Ryan KM. Splicing DNA-damage responses to tumour cell death. Biochim Biophys Acta. 2004 Dec 10;1705(1):3-15.

18. Prober DA, Edgar BA. Growth regulation by oncogenes--new insights from model organisms. Curr Opin Genet Dev. 2001 Feb; 11(1):19-26.

19. Oncogenes and cancer. En: Lewin B. Gene VI. Oxford: University; 1997. pp. 1131-72.

20. Oncogenes and cancer. En: Gene IX. Oxford: University,2006:

21. Sherr CJ. Cancer cell cycles. Science. 1996 Dec 6; 274(5293):1672-7

22. Marx J. How cells cycle toward cancer. Science. 1994 Jan 21; 263(5145):319-21

23. Vogelstein B, Kinszler KW. The multistep nature of cancer. Trends Genet. 1993 Apr; 9(4):138-41.

24. Bardelli A, Cahill DP, Lederer G, Speicher MR, Kinzler KW. Carcinogenspecific induction of genetic instability. Proc Natl Acad Sci U S A. 2001 May 8;98(10):5770-5.

25. Ríos Hernández M, Hernández Menéndez M. Los genes supresores de tumores y el cáncer. Rev Cubana Oncol. 2001;17(1):65-71

26. Werness BA, Levine AJ, Howley PM. Association of human papillomavirus types 16 and 18 E6 proteins with p53. Science. 1990 Apr 6; 248(4951):76-9.

27. Johnson DG, Cress WD, Jakoi L, Nevins JR. Oncogenic capacity of the E2F1 gene. Proc Natl Acad Sci U S A. 1994 Dec 20;91(26):12823-7.

28. Singh P, Wong SH. Hong W. Overexpression of E2F-1 in rat embryo fibroblast leads to neoplastic transformation. EMBO J. 1994 Jul 15 ; 13(14):3329-38.

29. Beijersbergen RL, Benards R. Cell cycle regulation by the retinoblastoma family of growth inhibitory proteins. Biochim Biophys Acta. 1996 Jun 7;1287(2-3):103-20

30. Holey P. Mechanistic role for human papilomavirus in human cancer. En: Forther J, Rhoads JE. Accomplishments in cancer research 1994. Philadelphia: Lippincott, $1995 ; 174$.
31. Adams JM, Cory S. The Bcl-2 apoptotic switch in cancer development and therapy. Oncogene. 2007: 26(9): 1324-37.

32. Wyllie AH, Kerr JF, Currie AR. Cell death: the significance of apoptosis. Int Rev Cytol. 1980; 68: 251-306

33. Bernards R, Weinberg RA. A progression puzzle. Nature. 2002; 418 (6900):823.

34. Nikiforov MA, Hagen K, Ossovskaya VS, Connor TM, Lowe SW, Deichman GI, et al. p53 modulation of anchorage independent growth and experimental metastasis. Oncogene 1996; 13 (8):1709-19.

35. Wallace-Brodeur RR, Lowe SW. Clinical implication of p53 mutation. Cell Mol Life Sci. 1999; 55(1): 64-75.

36. Vassileiv L.T. MDM2 Inhibitors for Cancer Therapy. Trends Mol Med. 2007 Jan;13(1):23-31

37. Hirata H, Hinoda Y, Kikuno N, Kawamoto K, Suehiro Y, Tanaka Y, Dahiya R. MDM2 SNP309 is associated with for susceptibility and poor prognosis in renal cell carcinoma. Clin Cancer Res. 2007 Jul 15; 13(14):4123-9.

38. Vazquez A, Bond EE, Levine AJ, Bond GL. The genetics of the p53 pathway, apoptosis and cancer therapy. Nat Rev Drug Discov. 2008 Dec; 7(12):979-87.

39. Ahmed S, Alpi A, Hengartner MO, Gartner A. C. elegans RAD-5/CLK2 defines a new DNA damage checkpoint protein. Curr Biol. 2001 Dec 11; 11(24):1934-44.

40. Buermeyer AB, Deschenes SM, Baker SM, Liskay RM. Mammalian DNA mismatch repair. Annu Rev Genet. 1999; 33:533-64.

41. Alpi A, Pasierbek P, Gartner A, Loidl J. Genetic and cytological characterization of the recombinationprotein RAD-51 in Caenorhabditis elegans. Chromosoma. $2003 \mathrm{Jul} ; 112(1): 6-16$.

42. Cantor SB, Bell DW, Ganesan S, Kass EM, Drapkin R, Grossman S, et al. $\mathrm{BACH} 1$, a novel helicase-like protein, interacts directly with BRCA1 and contributes to its DNA repair function. Cell. 2001 Apr 6;105(1):149-60.

43. Shrivastav M, De Haro LP, Nickoloff JA. Regulation of DNA Double-Strand break repair pathway choice. Cell Res. 2008 Jan;1 8 (1):134-47.

44. Cheung I, Schertzer M, Rose A, Lansdorp PM. High incidence of rapid telomere loss intelomerase-deficient Caenorhabditis elegans. Nucleic Acids Res. 2006 Jan 10; 34(1):96-103

45. Artandi SE, DePinho RA. Telomeres and telomerase in cancer. Carcinogenesis. 2010 Jan; 31(1):9-18.

46. Gale NW, Yancopoulos GD. Growth factors acting via endothelial cell-specific receptor tyrosine kinases: VEGFs, angiopoietins, and ephrins in vascular development. Genes Dev. 1999 May 1;13(9):1055-66

47. Chiang AC, Massagué J. Molecular basis of metastasis. N Engl J Med. 2008 Dec 25;359(26):2814-23.

48. McDermott U, Downing JR, Stratton MR. Genomics and the continuum of cancer care N Engl J Med. 2011 Jan 27; 364(4):340-50.

49. Nguyen M, Watanabe H, Budson AE, Richie JP, Hayes DF, Folkman J. Elevated levels of an angiogenic peptide, basic fibroblast growth factor, in the urine of patients with a wide spectrum of cancers. J Natl Cancer Inst. 1994 Mar 2;86(5):35661 .

50. Brunner G, Nguyen H, Gabrilove J, Rifkin DB, Wilson EL. Basic fibroblast growth factor expressing in human bone marrow and peripheral blood cells. Blood. 1993 Feb 1;81(3):631-8.

51. Baeriswyl V, Christofori G. The angiogenic switch in carcinogenesis. Semin Cancer Biol. 2009 Oct; 19(5):329-37.

52. Kessenbrock K, Plaks V, Werb Z. Matrix metalloproteinasas regulators of the tumor microenviroment. Cell. 2010 Apr 2; 141(1):52-67.

53. Negrini S, Gorgoulis VG, Halazonetis TD. Genomic instability- an evolving hallmark of cancer. Nat Rev Mol Cell Biol. 2010 Mar; 11(3):220-8

54. O'Reilly MS, Holmgren L, Shing Y, Chen C, Rosenthal RA, Moses M, et al. Angiostatin: a novel angiogenesis inhibitor that mediates the suppression of metastases by a Lewis lung carcinoma. Cell. 1994 Oct 21;79(2):315-28.

55. Berx G, van Roy F. Involvement of members of the cadherin superfamily in cancer. Cold Spring Harb Perspect Biol. 2009 Dec;1(6):a003129.

56. Hess KR, Varadhachary GR, Taylor SH, Wei W, Raber MN, Lenzi R, Abbruzzese JL. Metastatic patterns in adenocarcinoma. Cancer. $2006 \mathrm{Apr}$ $1 ; 106(7): 1624-33$. 